\title{
Cathepsin $L$ is essential for onset of autoimmune diabetes in NOD mice
}

\author{
René Maehr, ${ }^{1}$ Justine D. Mintern, ${ }^{1}$ Ann E. Herman, ${ }^{2}$ Ana-Maria Lennon-Duménil,, \\ Diane Mathis, ${ }^{2}$ Christophe Benoist, ${ }^{2}$ and Hidde L. Ploegh'
}

\begin{abstract}
1Department of Pathology, Harvard Medical School, Boston, Massachusetts, USA. ${ }^{2}$ Section on Immunology and Immunogenetics, Joslin Diabetes Center, and Department of Medicine, Brigham and Women's Hospital, Harvard Medical School, Boston, Massachusetts, USA.
\end{abstract}

\begin{abstract}
Lysosomal proteases generate peptides presented by class II MHC molecules to CD4 ${ }^{+} \mathrm{T}$ cells. To determine whether specific lysosomal proteases might influence the outcome of a $\mathrm{CD}^{+} \mathrm{T}$ cell-dependent autoimmune response, we generated mice that lack cathepsin $\mathrm{L}$ (Cat $\mathrm{L})$ on the autoimmune diabetes-prone NOD inbred background. The absence of Cat $\mathrm{L}$ affords strong protection from disease at the stage of pancreatic infiltration. The numbers of $\mathrm{I}-\mathrm{A}^{\mathrm{g}}$-restricted $\mathrm{CD}^{+} \mathrm{T}$ cells are diminished in Cat $\mathrm{L}$-deficient mice, although a potentially diabetogenic $\mathrm{T}$ cell repertoire persists. Within the $\mathrm{CD4}^{+} \mathrm{T}$ cell compartments of Cat $\mathrm{L}$-deficient mice, there is an increased proportion of regulatory $\mathrm{T}$ cells compared with that in Cat $\mathrm{L}$-sufficient littermates. We suggest that it is this displaced balance of regulatory versus aggressive $\mathrm{CD}^{+} \mathrm{T}$ cells that protects Cat $\mathrm{L}$-deficient mice from autoimmune disease. Our results identify Cat $\mathrm{L}$ as an enzyme whose activity is essential for the development of type I diabetes in the NOD mouse.
\end{abstract}

\section{Introduction}

IDDM, or type 1 diabetes, is an autoimmune disease characterized by destruction of insulin-producing $\beta$ cells in the islets of Langerhans (1). In humans and mice, the MHC region, in particular the class II MHC region, is a key susceptibility locus strongly associated with the disease (reviewed in refs. 2, 3). In humans, both HLADR and -DQ are associated with susceptibility to type 1 diabetes. In NOD mice, a structurally similar class II MHC molecule, I-A $\mathrm{A}^{\mathrm{g}}$, contributes to disease susceptibility (reviewed in refs. 3,4 ).

The class II MHC locus encodes molecules that bind antigenic peptides for presentation to $\mathrm{CD}^{+} \mathrm{T}$ cells. Class II MHC molecules are coassembled in the endoplasmic reticulum with a chaperone, the invariant chain (Ii). In endocytic compartments, Ii is progressively proteolyzed to yield a class II MHC-bound Ii remnant referred to as class II-associated invariant chain peptide (CLIP). Removal of CLIP by an accessory molecule, the nonclassical class II-dimer, H-2M, is required to allow peptide loading (reviewed in ref. 5). Interference with the proteolysis of Ii inhibits the formation of peptide-loaded class II MHC molecules (6-8) and thus might change the peptide repertoire presented. The endocytic proteases that mediate the final processing step from the small leupeptininduced peptide (SLIP) Ii fragment to the CLIP peptide are, to a large extent, cell-type specific and belong to the cathepsin (Cat) family $(9,10)$. In addition to Ii proteolysis, Cat family members also contribute to class II MHC antigen presentation through the generation of antigenic peptide epitopes $(11,12)$.

Cat $\mathrm{L}$ is involved in the proteolysis of class II MHC-associated Ii in cortical thymic epithelial cells (cTECs) (13) and is believed to influence the peptide repertoire presented by class II MHC molecules $(12,14)$. However, the action of lysosomal proteases, notwith-

Nonstandard abbreviations used: Cat, cathepsin; CIITA, class II transactivator; CLIP, class II-associated invariant chain peptide; cTEC, cortical thymic epithelial cell; Ii, invariant chain; LHVS, N-morpholinurea-leucine-homophenylalanine-vinylsulfone-phenyl; SLIP, small leupeptin-induced peptide.

Conflict of interest: The authors have declared that no conflict of interest exists.

Citation for this article: J. Clin. Invest. 115:2934-2943 (2005).

doi:10.1172/JCI25485. standing their acidic $\mathrm{pH}$ optimum, is not necessarily limited to the endosomal system. Secreted lysosomal proteases can degrade components of the extracellular matrix (reviewed in ref. 15) and might thus regulate cell migration. Usage of a nonconventional start codon in the cat $L$ gene yields a form of Cat $L$ with nuclear localization capable of processing certain transcription factors (16).

Here we investigate the role of Cat L in the NOD mouse, a model for spontaneous autoimmune diabetes. To this end, a genetic disruption of the cat $L$ gene was backcrossed onto the NOD background. Cat L deficiency protects diabetes-prone mice from insulitis and subsequent diabetes. This protection is not due to inefficient clearance of Ii remnants from I- $\mathrm{A}^{\mathrm{g} 7}$ molecules, nor does it seem to be caused by abrogation of antigen presentation in Cat Ldeficient NOD mice. Rather, Cat L-deficient mice display a defect in the generation of $\mathrm{CD}^{+} \mathrm{T}$ cells that leads to an increase in the proportion of $\mathrm{CD} 4^{+} \mathrm{CD} 25^{+} \mathrm{T}$ cells in the peripheral $\mathrm{CD} 4^{+} \mathrm{T}$ cell compartment compared with that in wild-type controls. We suggest that this change in the $\mathrm{CD} 4^{+} \mathrm{T}$ cell compartment accounts for the resistance to diabetes seen in Cat L-deficient NOD mice.

\section{Results}

Cat L-deficient NOD mice are protected from insulitis and diabetes. To explore the role of Cat $\mathrm{L}$ in the development of type 1 diabetes, we bred the cat $L$-null mutation (17) onto the NOD background. After 10-12 backcross generations, heterozygous mice were intercrossed to obtain congenic Cat L-deficient NOD mice together with wild-type and heterozygous littermates. Cat L-deficient NOD mice and control littermates were tested for onset of diabetes. Whereas Cat $\mathrm{L}$ heterozygous and wild-type littermates progressed to diabetes, the Cat L-deficient NOD mice were protected from diabetes (Figure 1A). The difference in cumulative diabetes onset at 29 weeks of age for Cat L-deficient compared with wildtype NOD mice was statistically significant $(P<0.001)$. Even at 47 weeks of age, all Cat L-deficient NOD mice analyzed $(n=12)$ were diabetes-free (data not shown).

Diabetes results from the destruction of the pancreatic $\beta$ cells and is preceded by an influx of mixed leukocyte populations into 

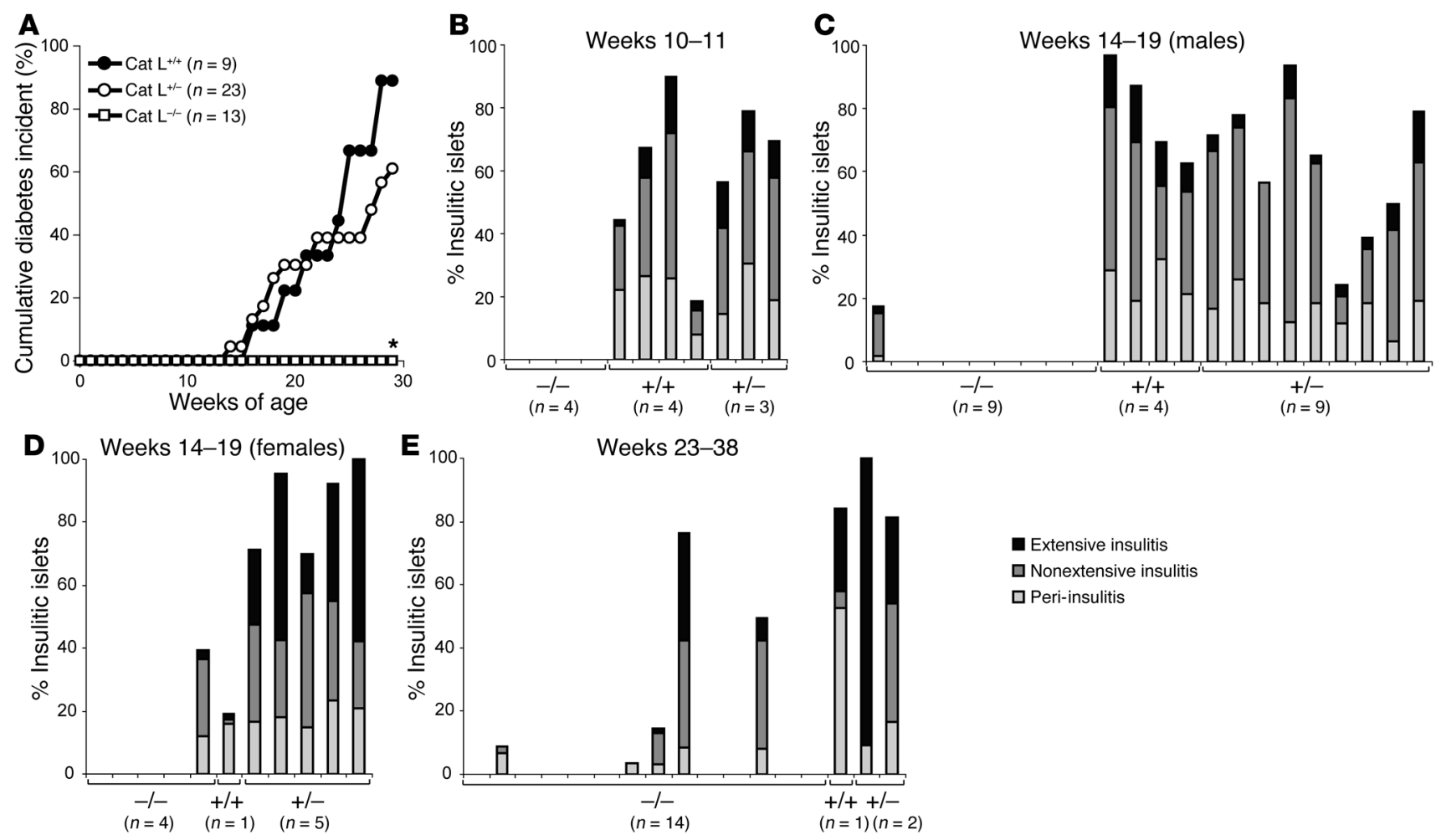

Figure 1

Cat L-deficient mice are protected from pancreatic insulitis. (A) Diabetes frequency was determined by measurement of urine glucose levels in Cat L-deficient (Cat L-/-, open squares, $n=13$ ), Cat $\mathrm{L}$-heterozygous (Cat $\mathrm{L}^{+/-}$, open circles, $n=23$ ), and Cat $\mathrm{L}-$ wild-type $\left(C a t \mathrm{~L}^{+/+}\right.$, filled squares, $n=9$ ) female NOD mice. *Statistical analysis by the $\chi^{2}$ test yielded a value of $P<0.001$ for diabetes incidence in 29 -week-old Cat L-deficient compared with wild-type NOD mice. (B) At 10-11 weeks of age, Cat L-deficient mice (-/-) together with control wild-type (+/+) and heterozygous (+/-) littermates were analyzed for insulitis by scoring histological analysis. Insulitis was characterized as peri-, nonextensive, or extensive depending on the level of infiltration. Peri-insulitis is reflected as a noninvasive leukocyte accumulation outside the pancreatic islet whereas nonextensive insulitis describes an invasive infiltrate in the pancreatic islet. In extensive insulitis, more than $50 \%$ of the individual pancreatic islet is infiltrated or destroyed. Each bar represents an individual mouse. (C and D) At 14-19 weeks of age, male and female Cat $L$-deficient animals and control littermates were analyzed for infiltration of the pancreas. (E) Levels of insulitis present in 23- to 38-week-old Cat L-deficient NOD mice and control littermates were determined. Mice examined in the 23- to 38-week age groups were female except for 2 Cat L-deficient male NOD mice.

the pancreatic islets (insulitis) starting at 3-4 weeks after birth (reviewed in ref. 18). To determine whether Cat L deficiency impairs the onset of insulitis, we examined histological sections for the presence of insulitis in Cat L-deficient NOD mice and littermate controls. In 10- to 11-week-old animals, none of the Cat L-deficient NOD mice exhibited infiltration of the pancreas, whereas control littermates showed typical infiltration, ranging from peri-insulitis to extensive insulitis (Figure 1B). To analyze whether the absence of insulitis in Cat L-deficient NOD mice was sex dependent or due to a delay in infiltration rather than protection from insulitis, we analyzed pancreatic sections from 14- to 19-week-old female and male mice. At this later age, 1 out of 9 male and 1 out of 4 female Cat L-deficient NOD mice showed signs of insulitis (Figure 1, C and D), indicating that strong protection occurs independently of sex. The difference in severity of insulitis in 14- to 19-week-old Cat L-deficient NOD mice and wild-type littermates was statistically significant $(P<0.001$; Table 1$)$.

Table 1
Even at 23 to 38 weeks, only 5 out of 12 female and none of the 2 male Cat L-deficient mice showed signs of insulitis (Figure 1E). In contrast, all of the female Cat L-sufficient $(n=3)$ animals showed extensive infiltration of the pancreas (Figure 1E) or had developed diabetes by this time point (Figure 1A). Cat L deficiency thus protects NOD mice from diabetes and affords strong protection from infiltration of the pancreas.

Ii remnants do not accumulate with $I-A^{g 7}$ molecules upon disruption of Cat L or Cat S function. The protection from diabetes in Cat L-

Frequency of insulitis in 14- to 19-week-old Cat L-deficient and Cat L-sufficient NOD mice

$\begin{array}{llrcc} & \text { Clean islets } & \text { Peri-insulitis } & \text { Nonextensive insulitis } & \text { Extensive insulitis } \\ \text { Cat } \mathrm{L}^{-/-}(n=14) & 95.9( \pm 3.0)^{\mathrm{A}} & 1.0( \pm 0.9)^{\mathrm{A}} & 2.7( \pm 1.9)^{\mathrm{A}} & 0.4( \pm 0.2)^{\mathrm{A}} \\ \text { Cat } \mathrm{L}^{+++}(n=5) & 33.0( \pm 13.4) & 23.5( \pm 3.1) & 31.7( \pm 9.2) & 11.8( \pm 2.9) \\ \text { Cat } \mathrm{L}^{+/-}(n=14) & 29.6( \pm 5.9) & 17.3( \pm 1.3) & 36.2( \pm 4.2) & 16.9( \pm 5.1)\end{array}$

Level of insulits was scored for the indicated numbers of mice ( $>30$ islets per mouse). Results are expressed as mean \pm SEM, and significant differences between Cat L-deficient and wild-type NOD mice are indicated. ${ }^{A} P<0.001$. 
deficient animals might be due to an impairment of class II $\mathrm{MHC}-$ restricted antigen presentation. Ii remnants accumulate in complex with class II MHC molecules in dendritic cells and B cells upon interference with Cat S activity (19-21) and in cTECs upon disruption of the cat $L$ gene (13). Occupation of the class II MHC peptide binding groove by Ii remnants might impair presentation of peptides that trigger an autoimmune response. The accumulation of Ii remnants upon inactivation of Cat $\mathrm{L}$ or $\mathrm{S}$ is influenced by the MHC polymorphism and is seen in $\mathrm{H}-2^{\mathrm{b}}$ but not $\mathrm{H}-2^{\mathrm{q}}$ mice (13, $14,20,22)$. The behavior of the NOD haplotype $\mathrm{H}-2^{\mathrm{g} 7}$ with respect to clearance of Ii remnants is unknown.

To examine whether Ii remnants might accumulate in the absence of Cat $\mathrm{L}$ in the thymus, a tissue that has been shown to rely on Cat $\mathrm{L}$ activity for Ii proteolysis in mice of the $\mathrm{H}-2^{\mathrm{b}}$ haplotype (13), we analyzed Cat L-deficient NOD and control mice for the presence of such remnants. The Ii remnants were readily detectable by immunoblotting of thymic extracts from Cat L-deficient $\mathrm{H}-2^{\mathrm{b}}$ mice but were absent from wild-type $\mathrm{H}-2^{\mathrm{b}}$ mice and Cat L-deficient and wild-type $\mathrm{H}-2^{\mathrm{g} 7}$ mice (Figure $2 \mathrm{~A}$ ). The overall levels of the Ii splice variants p31 and p41 were equivalent for Cat L-deficient and wild-type thymi, demonstrating equal gel loading and similar amounts of Ii splice variants at steady state in the thymi of $\mathrm{H}-2^{\mathrm{b}}$ and $\mathrm{H}-2^{\mathrm{g} 7}$ animals. We conclude that Cat $\mathrm{L}-$ mediated proteolysis of the Ii remnant SLIP is not a prerequisite for its dissociation from the $\mathrm{I}-\mathrm{A}^{\mathrm{g}}$ complex.

In processing of the SLIP Ii remnant, Cat $S$ has a role in B cells and dendritic cells similar to that of Cat $\mathrm{L}$ in cTECs (reviewed in refs. 9, 10, 23). Therefore, splenocytes were used as a source for B cells to examine whether class II MHC molecules of NOD mice $\left(\mathrm{I}-\mathrm{A}^{\mathrm{g}}\right)$ accumulate Ii remnants transiently upon inhibition of Cat $\mathrm{S}$ activity. We pulse labeled either NOD (H-2 $\left.{ }^{\mathrm{g} 7}\right)$ or control C57BL/6 $\left(\mathrm{H}-2^{\mathrm{b}}\right)$ splenocytes with $\left.{ }^{35} \mathrm{~S}\right]$-methionine and chased for 4 hours in the presence or absence of $\mathrm{N}$-morpholinurea-leucine-homophenylalanine-vinylsulfone-phenyl (LHVS), a Cat S-specific inhibitor $(19,24)$. We used a polyclonal rabbit serum directed against the cytoplasmic tail of the class II MHC $\beta$ chain to allow the recovery of all $\beta$ subunits, associated $\alpha$ chains, and associated Ii chain splice forms (p41 and p31). Class II MHC molecules loaded with peptide $(\alpha \beta p)$ are SDS-stable complexes and dissociate upon boiling into their constituent subunits (25). In untreated C57BL/6 splenocytes, such SDS-stable complexes were readily detectable at the 4-hour chase point (Figure 2B). Disruption of Cat S activity by LHVS treatment led to impaired generation of this complex. I- $\mathrm{A}^{\mathrm{b}}$ class II MHC molecules remained associated with SLIP Ii remnants $(\alpha \beta S L I P)$ (Figure 2B) (22). This complex was partly SDS stable and dissociated into its subunits upon boiling. We confirmed that the formation of SDS-stable complexes was less efficient for I-Ag7 molecules in NOD splenocytes (Figure 2B) $(26,27)$. In contrast to I-A ${ }^{\mathrm{b}}$ molecules, the Ii SLIP remnant did not accumulate in a complex with I-Ag7 class II MHC molecules upon disruption of Cat $S$ function by LHVS treatment. This suggests that Ii remnants are efficiently cleared from the class II MHC molecules in the NOD background even upon Cat $\mathrm{S}$ inhibition. However, one explanation for the low recovery of SLIP coimmunoprecipitated with the I-Ag7 molecule might be a loss of the complex after lysis. The I-Ag7:SLIP

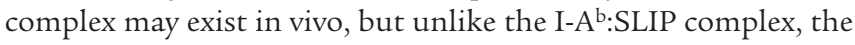
association may be of insufficient strength to allow coimmunoprecipitation. To address this concern, we immunoprecipitated Ii from splenocytes. For both I-A ${ }^{\mathrm{b}}$ and I-A $\mathrm{A}^{\mathrm{g}}$, Ii as well as class II MHC $\alpha$ and $\beta$ chains were immunoprecipitated, but $\alpha \beta p$ complexes were not (Figure 2C). Upon disruption of Cat S activity by LHVS treatment, SLIP accumulated in association with the I-A ${ }^{\mathrm{b}}$ molecule in SDS stable complexes and dissociated into corresponding subunits upon boiling. However, no such Ii remnant could be immunoprecipitated from LHVS-treated NOD splenocytes (Figure $2 \mathrm{C})$. We conclude that the processing of Ii by Cat $\mathrm{S}$ is not required to allow removal of Ii remnants in the NOD haplotype.

Together our data suggest that Ii remnants in the NOD haplotype are efficiently cleared from the class II MHC molecules, independently of Cat L and Cat S activity. Thus, blockade of I-Ag7

A

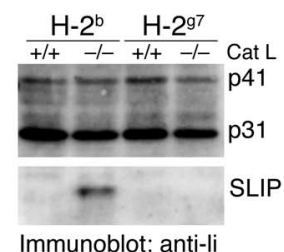

B

NOD/Lt
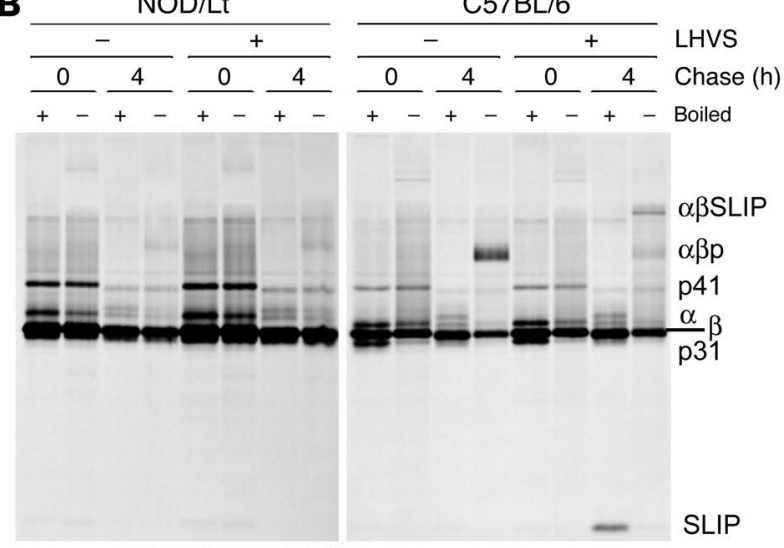

Immunoprecipitation: anti-I-A $\beta$

C

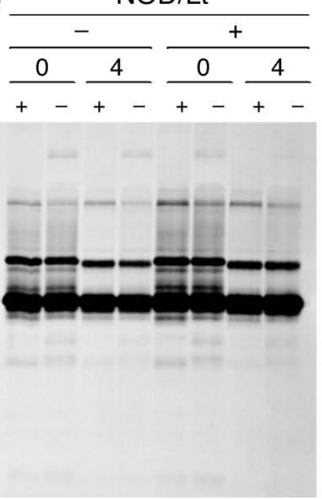

Immunoprecipitation: anti-li

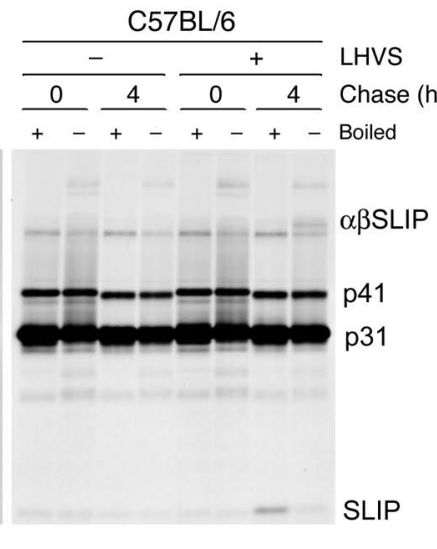

Figure 2

Impairment of Cat $L$ or Cat $S$ activity does not lead to accumulation of I-A ${ }^{97}$ molecule-associated li remnants. (A) Immunoblot for li on thymic extracts derived from Cat $\mathrm{L}$-deficient or wild-type mice of $\mathrm{H}-2^{\mathrm{b}}$ or $\mathrm{H}-2^{97}$ haplotype. (B) NOD- or C57BL/6-derived splenocytes were pulsed and chased in the presence or absence of LHVS. Samples were immunoprecipitated for class II MHC molecules or (C) for li with rabbit polyclonal antiserum. Formation of SDS-stable class II MHC complexes was assessed under mildly denaturing conditions (nonboiled) as indicated. The subunits of class II MHC molecules ( $\alpha$ and $\beta)$ and complexes with peptide $(\alpha \beta p)$ or li remnants $(\alpha \beta S L I P)$ are indicated. li isoforms (p31 and p41) and remnants (SLIP) are shown. 


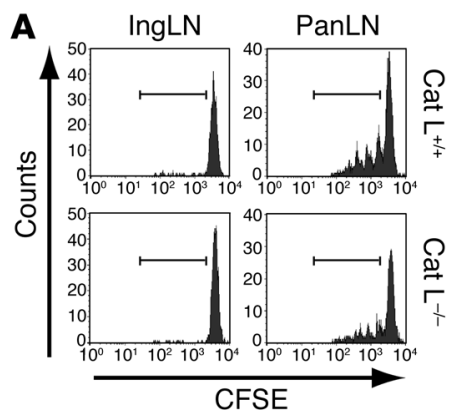

C

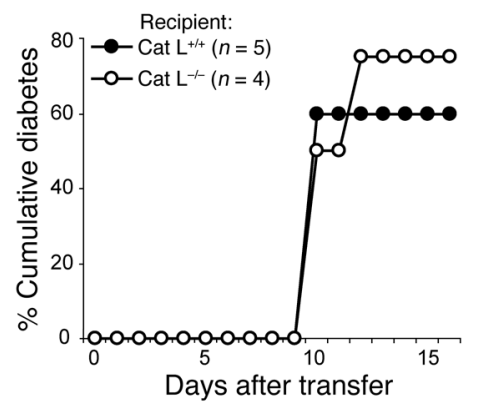

B
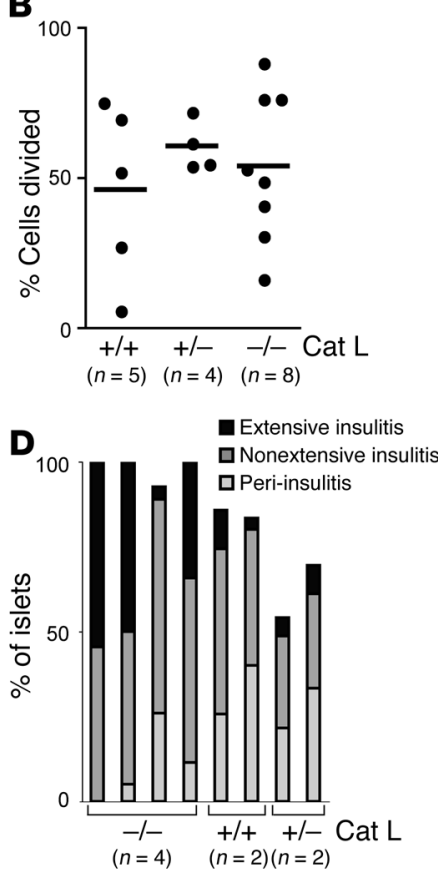

\section{Figure 3}

Antigen presentation proceeds normally in Cat L-deficient mice. (A) CFSE-labeled BDC2.5 splenocytes were transferred into wild-type, Cat L-heterozygous, or Cat L-deficient mice. T cell proliferation was assessed 65 hours later by CFSE dilution in the $\mathrm{CD} 4^{+} \mathrm{T}$ cell population. The percentage of $\mathrm{CD} 4^{+} \mathrm{T}$ cells that exhibited dilution of CFSE as a result of cell division was determined for cells falling into the region of CFSE-positive cells that underwent at least 1 cell division (indicated by the bar). IngLN, inguinal lymph node; PanLN, pancreatic lymph node. (B) Results of 3 or more independent CFSE transfer experiments are summarized for wild-type $(n=5)$, Cat Lheterozygous ( $n=4)$, and Cat L-deficient $(n=8)$ recipients; each point represents an individual mouse. (C) A total of $5 \times 10^{5}$ BDC2.5/NOD donor splenocytes were injected i.p. into Cat L-deficient NOD/Scid mice $(n=4)$ or wild-type controls $(n=5)$. Diabetes incidence was determined by urine glucose levels. (D) Splenocytes from recently diabetic mice were injected into sublethally irradiated Cat L-deficient NOD mice or wild-type and heterozygous controls. Insulitis was determined on histological nonconsecutive sections. The number of mice used in the experiments is indicated. molecules by Ii remnants is not likely to be a cause of decreased or altered antigen presentation in Cat L-deficient NOD mice.

Presentation of pancreatic antigen occurs in the absence of Cat $L$. Cat $L$ is expressed in various cell types and might play a role in proteolysis of protein antigens. To examine whether the Cat L deficiency interferes with presentation of pancreatic antigens to $\mathrm{CD} 4^{+} \mathrm{T}$ cells, we employed an adoptive transfer system. BDC2.5 TCR transgenic NOD mice possess $\mathrm{CD}^{+} \mathrm{T}$ cells that express a diabetogenic TCR specific for an unknown pancreatic islet antigen presented in the context of the NOD I-A $\mathrm{g}^{7}$ molecules (28). The proliferation of transferred, CFSE-labeled BDC2.5/NOD T cells is reflected by progressive dilution of the dye upon cell division in the pancreatic lymph node. The transferred BDC2.5/NOD T cells divided to a similar extent in wild-type and Cat L-deficient NOD recipients in response to antigen presented in the pancreatic lymph node that drains the pancreas (Figure 3, A and B). No division was observed for BDC2.5/NOD T cells homing to the inguinal lymph node, where pancreatic antigen is not presented (Figure $3 \mathrm{~A}$ and data not shown). Thus, the pancreatic lymph nodes of Cat L-deficient mice contain cells that are capable of presenting a naturally occurring autoantigen, resulting in $\mathrm{T}$ cell activation.

Given the ability of diabetogenic T cells to be activated in the pancreatic lymph node, we then addressed whether $\beta$ cell-reactive $T$ cells can gain access to the pancreatic islets in the absence of Cat $\mathrm{L}$. To avoid a contribution of the $\mathrm{T}$ cells of the recipient to the progression of an autoimmune response after transfer of diabetogenic T cells, we generated Cat L-deficient NOD/Scid mice. After transfer of diabetogenic BDC2.5/NOD splenocytes into Cat L-deficient and wild-type NOD/Scid mice, the onset of diabetes was very similar in both cohorts (Figure 3C). Therefore, the Cat L-deficient mice provide an environment that allows $\mathrm{T}$ cell activation and their subsequent infiltration into the pancreas.

To determine whether Cat L-deficient NOD mice are susceptible to insulitis or destruction of pancreatic islets by a wild-type $\mathrm{T}$ cell repertoire, we transferred splenocytes from recently dia- betic NOD mice into sublethally irradiated Cat L-deficient NOD mice or control littermates. Cat L-deficient NOD hosts readily exhibited signs of insulitis 6 weeks after transfer (Figure 3D). We conclude that the Cat L-deficient pancreas is accessible to T cells and that the islets can be targeted and destroyed by effector lymphocytes. Cat L deficiency therefore does not impair peripheral antigen presentation to the extent that pancreatic autoantigens in general are no longer presented.

Cat L-deficient NOD mice display a defect in the generation of $C D 4^{+}$thymocytes. Cat L-deficient mice exhibit a thymic selection defect that impairs the generation of I-A $\mathrm{A}^{\mathrm{b}}$ and I-A ${ }^{\mathrm{q}}-$ restricted $\mathrm{CD}^{+} \mathrm{T}$ cells $(13,14)$. To address whether thymic selection is defective for $\mathrm{CD}^{+}$ $\mathrm{T}$ cells restricted to other MHC haplotypes, we analyzed Cat Ldeficient mice on the $129 \times \mathrm{x} 57 \mathrm{BL} / 6$ mixed background $\left(\mathrm{H}-2^{\mathrm{b}}\right)$, $\mathrm{NOD}\left(\mathrm{H}-2^{\mathrm{g}}\right)$, and Balb/c (H-2 $)$ backgrounds. Analysis of the thymocyte populations from Cat $\mathrm{L}$-deficient mice revealed a strong reduction in relative and absolute $\mathrm{CD}^{+}$cell numbers but not $\mathrm{CD} 8^{+}$ thymocytes for these haplotypes (Figure 4, A and B, and Tables 2 and 3). Cat L-heterozygous NOD mice possessed populations of $\mathrm{CD}^{+} \mathrm{T}$ cells comparable with those of wild type, indicating the absence of a gene dosage effect (Figure 4B and Tables 2 and 3). We conclude that the thymic selection defect that occurs in mice lacking Cat L is largely independent of the class II MHC haplotype.

To examine whether BDC2.5 T cells were selected in Cat L-deficient NOD animals, we generated Cat L-deficient BDC2.5/NOD mice. Similar to Cat L-deficient NOD mice, thymic selection of $\mathrm{CD}^{+} \mathrm{T}$ cells was impaired in Cat L-deficient BDC2.5/NOD mice (Figure 4C). To address whether the defect was $\mathrm{T}$ cell autonomous, we generated bone marrow chimeras by transferring $\mathrm{T}$ cell-depleted BDC2.5 Thy $1.1^{+}$bone marrow cells into lethally irradiated Cat Ldeficient or control littermate NOD mice. Bone marrow-reconstituted Cat L-deficient NOD mice exhibited a strong decrease in the proportion of $\mathrm{CD}^{+}$compartments when compared with control mice (Figure 4D). Therefore the defect is attributable to the lack of Cat $\mathrm{L}$ expression in the radio-resistant thymic stroma. Thus, reduced 
A
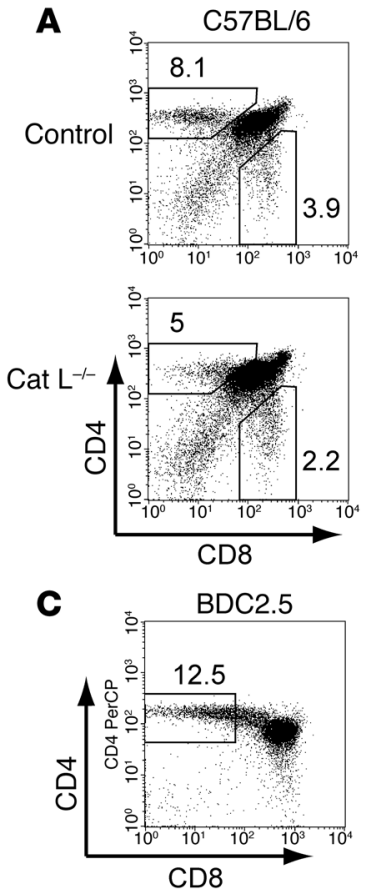
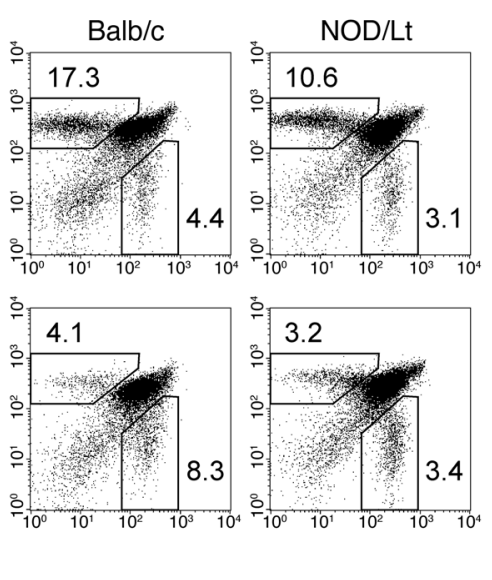

B

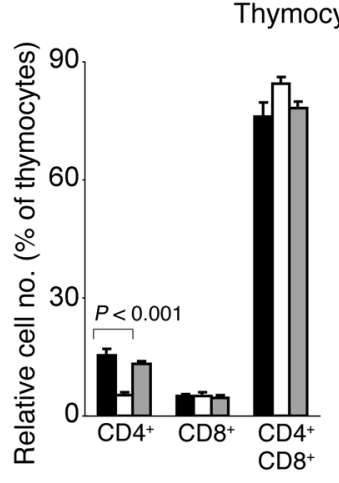

yte populations

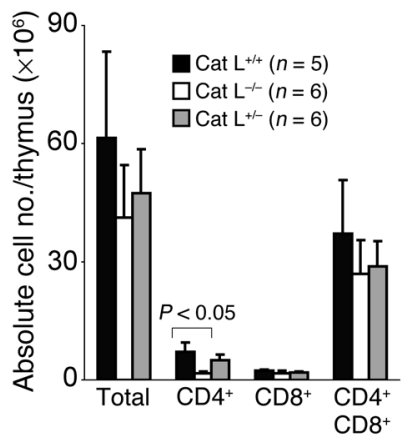

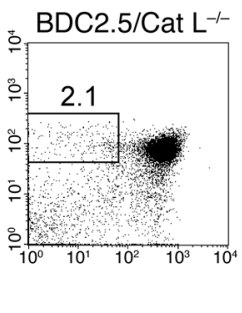

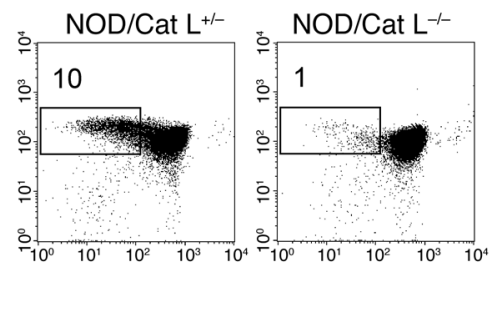

Figure 4

Cat $\mathrm{L}-$ deficient mice exhibit a thymic selection defect on $\mathrm{H}-2^{\mathrm{b}}, \mathrm{H}-2^{\mathrm{d}}$, and $\mathrm{H}-2^{\mathrm{g} 7}$ backgrounds. (A) Thymocytes of adult Cat $\mathrm{L}-$ deficient $\mathrm{C} 57 \mathrm{BL} / 6$ $\left(\mathrm{H}-2^{b}\right)$, Balb/c $\left(\mathrm{H}-2^{\mathrm{d}}\right)$, and NOD/Lt $\left(\mathrm{H}-2^{\mathrm{g} 7}\right)$ Cat L-sufficient controls were examined by cytofluorometry staining for CD4 and CD8 $\alpha$ cell surface expression. The percentage of CD4+ $\mathrm{T}$ cells is indicated for a representative experiment. (B) Relative (left panel) and absolute (right panel) numbers of $\mathrm{CD}^{+}, \mathrm{CD}^{+}$, and $\mathrm{CD} 4^{+} \mathrm{CD} 8^{+}$thymocyte populations in Cat L-deficient and -heterozygous and wild-type NOD mice are displayed. The results represent the mean number of mice \pm SEM as experimental error. $P$ values for significant differences in cell populations between Cat $L-$ deficient and wild-type NOD mice are indicated. (C) Cell surface expression of CD4 and CD8 $\alpha$ was assessed by cytofluorometry on thymocytes of BDC2.5/Cat L and wild-type BDC2.5 mice or (D) on thymocytes 6 weeks after bone marrow reconstitution by BDC2.5 Thy 1.1+ donors into Cat Ldeficient or Cat L-sufficient NOD mice recipients. The thymocytes were gated on Thy $1.1^{+}$cells.

$\mathrm{CD}^{+} \mathrm{T}$ cell numbers or alterations in thymic selection are likely to contribute to the lack of diabetes in Cat L-deficient NOD mice.

The $T$ cell compartment of Cat L-deficient mice exhibits a higher $\mathrm{CD} 4^{+} \mathrm{CD} 25^{+}$to $\mathrm{CD} 4^{+} \mathrm{T}$ cell ratio. The thymic selection defect observed in Cat L-deficient mice results in $\mathrm{CD}^{+} \mathrm{T}$ cell lymphopenia in the periphery of $\mathrm{H}-2^{\mathrm{b}}$ and $\mathrm{H}-2^{\mathrm{q}}$ haplotype animals $(13,14)$. To determine whether the Cat L-deficient NOD mice exhibit a similar peripheral defect, we compared the number of peripheral $\mathrm{CD}^{+}$ $\mathrm{T}$ cells in Cat L-deficient mice with that of wild-type littermates. The proportion of $\mathrm{CD}^{+} \mathrm{T}$ cells in Cat $\mathrm{L}$-deficient NOD mice was reduced by approximately $70 \%$ in the spleen when compared with wild-type controls (Figure 5A and Table 4). The basis for the reduction was a loss of $\mathrm{CD}^{+} \mathrm{T}$ cells rather than the increase in a different splenocyte population, as the absolute number of $\mathrm{CD}^{+}$cells was reduced (Table 5). Although this is a significant reduction in peripheral $\mathrm{CD} 4^{+} \mathrm{T}$ cells, many $\mathrm{CD} 4^{+} \mathrm{T}$ cells remain; yet these fail to cause diabetes in the absence of Cat $\mathrm{L}$.

We then examined $\mathrm{CD}^{+} \mathrm{T}$ cell subpopulations in 10 -week-old Cat $\mathrm{L}$-deficient NOD mice. The proportion of $\mathrm{CD} 4^{+} \mathrm{CD} 25^{+}$cells present in the $\mathrm{CD}^{+} \mathrm{T}$ cell population was increased in Cat Ldeficient mice (Figure 5A). This population is known to contain cells with important immunoregulatory functions (29, 30). We analyzed the surface expression of CD69 and CD45RB on $\mathrm{CD}^{+} \mathrm{CD} 25^{+} \mathrm{T}$ cells to further distinguish regulatory $\mathrm{T}$ cells from activated $\mathrm{T}$ cells. Regulatory function has been attributed to $\mathrm{CD}^{+} \mathrm{CD} 25^{+} \mathrm{CD} 45 \mathrm{RB}^{\text {low }}(31,32)$ as well as $\mathrm{CD} 4{ }^{+} \mathrm{CD} 25^{+} \mathrm{CD} 69^{\text {low }}$ cells (33). In each subset possessing a regulatory phenotype, an increased proportion of regulatory $\mathrm{CD}^{+} \mathrm{T}$ cells was observed in Cat L-deficient NOD mice (Figure 5A and Table 4).

The forkhead transcription factor Foxp3 is the best marker for regulatory $\mathrm{CD}^{+} \mathrm{T}$ cell subsets to date. This molecule is highly expressed in $\mathrm{CD} 4^{+} \mathrm{CD} 25^{+} \mathrm{T}$ regulatory cells $(32,34,35)$. To test whether the increased proportion of putative regulatory $\mathrm{T}$ cells in the $\mathrm{CD}^{+} \mathrm{T}$ cell compartment of Cat L-deficient NOD mice is reflected by an increase in Foxp3 expression, we sorted $\mathrm{CD}^{+}$and CD8 $\alpha^{+} \mathrm{T}$ cells from splenocytes of Cat L-deficient NOD mice and wild-type littermates. Real-time quantitative PCR analysis showed an increase in Foxp3 expression by 2- to 5-fold in Cat L-deficient $\mathrm{CD}^{+} \mathrm{T}$ cells relative to wild type (Figure $5 \mathrm{~B}$ ). As expected, CD8 ${ }^{+}$

Table 2

Proportion of thymocyte populations in Cat L-deficient and Cat L-sufficient NOD mice

\section{CD4-CD8- CD4 $^{+}{ }^{-}{ }^{-} 8^{+} \quad \mathrm{CD}^{+} \quad \mathrm{CD}^{+}$}

Cat L ${ }^{-/-}(n=6) \quad 4.9( \pm 1.0) \quad 84.4( \pm 1.8) \quad 5.3( \pm 0.7)^{\mathrm{A}} \quad 5.1( \pm 0.8)$

Cat $\mathrm{L}^{+/+}(n=5) \quad 4.8( \pm 1.0) \quad 76.2( \pm 3.4) \quad 15.4( \pm 1.5) \quad 5.1( \pm 0.3)$

Cat L+/- $(n=6) \quad 4.8( \pm 0.8) \quad 78.2( \pm 1.6) \quad 13.2( \pm 0.7) \quad 4.6( \pm 0.5)$

Proportions of $\mathrm{CD}^{-}{ }^{-C D} 8^{-}, \mathrm{CD}^{+}{ }^{+} \mathrm{CD}^{+}, \mathrm{CD}^{+}$, and $\mathrm{CD}^{+}$thymocytes (in \%) are displayed. Results are expressed as mean \pm SEM.

Significant results are indicated. ${ }^{\mathrm{A}} P<0.001$. 
Table 3

Absolute numbers of thymocytes in Cat L-deficient and Cat L-sufficient NOD mice

$\begin{array}{lcccc} & \text { Total thymocytes } & \text { CD4 }^{+} \mathbf{C D 8}^{+} & \text {CD4 }^{+} & \text {CD8 }^{+} \\ \text {Cat } \mathrm{L}^{-/-}(n=6) & 41.1( \pm 13.3) & 27( \pm 8.5) & 1.7( \pm 0.5) & 1.7( \pm 0.5) \\ \text { Cat } \mathrm{L}^{+/+}(n=5) & 61.5( \pm 21.8) & 37.2( \pm 13.4) & 7.1( \pm 2.3) & 2.4( \pm 0.2) \\ \text { Cat } \mathrm{L}^{+-}(n=6) & 47.4( \pm 11.2) & 28.8( \pm 6.4) & 5.1( \pm 1.3) & 1.8( \pm 0.4)\end{array}$

Absolute numbers of thymocytes $\left(\times 10^{6}\right)$ including CD4-CD8-, CD4 ${ }^{+} \mathrm{CD} 8^{+}$, $\mathrm{CD}^{+}$, and $\mathrm{CD} 8^{+}$thymocytes are displayed. Results are expressed as mean \pm SEM.

T cells did not express significant levels of Foxp3 (Figure 5B) (35). This result indicates an increased ratio of regulatory $\mathrm{CD}^{+} \mathrm{T}$ cells over normal $\mathrm{CD} 4^{+} \mathrm{T}$ cells in Cat $\mathrm{L}$-deficient mice.

To determine whether $\mathrm{T}$ cells from Cat $\mathrm{L}$-deficient NOD mice retain diabetogenic potential, we transferred splenocytes from Cat L-deficient NOD mice into NOD/Scid mice. Only 1 of 11 NOD/Scid recipients of Cat L-deficient NOD splenocytes progressed to diabetes 62 days after transfer (Figure 5C). Depletion of $\mathrm{CD} 4^{+} \mathrm{CD} 25^{+}$cells prior to transfer significantly increased the onset of disease at 42 weeks after transfer $(P<0.05)$. Transfer of $\mathrm{CD} 4^{+} \mathrm{CD} 25^{+}$-depleted Cat L-sufficient NOD splenocytes provoked diabetes in NOD/Scid mice more efficiently than transfer of Cat Ldeficient NOD splenocytes. This suggests that, in addition to the imbalance of regulatory $\mathrm{T}$ cells in the $\mathrm{CD} 4^{+} \mathrm{T}$ cell population, the impairment in overall $\mathrm{CD} 4^{+} \mathrm{T}$ cell numbers in Cat $\mathrm{L}$-deficient mice may influence the progression of disease in these animals.

These data imply that the $\mathrm{T}$ cell repertoire in Cat $\mathrm{L}$-deficient NOD mice retains diabetogenic potential that is suppressed by an increased proportion of regulatory $\mathrm{T}$ cells in the $\mathrm{CD} 4^{+} \mathrm{T}$ cell compartment.

\section{Discussion}

Lysosomal proteases influence peptide loading of class II MHC molecules via the generation of Ii intermediates and through degradation of antigenic proteins. Here we examine the role of a lysosomal protease, Cat $\mathrm{L}$, on the progression of autoimmune diabetes using the NOD mouse model. We demonstrate strong protection at the early stages of disease onset in Cat L-deficient NOD mice.

As usual in such backcross experiments, it is impossible to formally rule out that a closely linked protective locus, cosegregating with the mutation, is responsible for the altered diabetes phenotype. This is unlikely to be the case in this instance because no strong Idd loci in the vicinity of the cat $L$ gene on chromosome 13 have been reported $(36,37)$ and because an impairment in the $\mathrm{CD} 4^{+} \mathrm{T}$ cell population is consistent with prior observations in which the Cat L deficiency was placed on other genetic backgrounds $(13,14)$.

Accumulation of Ii remnants was not detected in thymic extracts of Cat L-deficient NOD mice as was observed in Cat L-deficient $129 \times \mathrm{C} 57 \mathrm{BL} / 6$ mice. Likewise, we observed efficient clearance of Ii intermediates from I-A $\mathrm{g}^{7}$ class II MHC molecules in splenocytes upon inhibition of Cat S. The lack of accumulation of Ii remnants in complex with I-Ag7 upon disruption of Cat $\mathrm{S}$ or Cat $\mathrm{L}$ is similar to that observed for the I-Aq molecule and in contrast to I- $\mathrm{A}^{\mathrm{b}}$ class II MHC molecules $(13,14,20,38)$. In any event, the protection from diabetes in the Cat L-deficient NOD mice is unlikely to result from a paucity of class II MHC molecules available for peptide loading due to the persistence of Ii remnants.

Antigen presentation relevant for the initiation of autoimmune diabetes in NOD mice occurs in the lymph node that drains the pancreas $(39,40)$. Although the exact subpopulation(s) of antigenpresenting cells involved in the priming of diabetogenic $\mathrm{CD} 4^{+} \mathrm{T}$

\section{Figure 5}

Cat $\mathrm{L}-$ deficient mice exhibit a relative increase of CD4 ${ }^{+}{ }^{-} D 25^{+}$to $\mathrm{CD}^{+}{ }^{+} \mathrm{CD} 25^{-}$cells. (A) Cytofluorometry analysis of splenic lymphocytes (left 4 panels) for CD4, CD8 $\alpha$, and CD25 surface expression. CD4+ lymphocytes (right 4 panels) are resolved for surface expression of CD25 together with their CD45RB and CD69 expression profiles. (B) Relative Foxp3 expression in $\mathrm{CD}^{+}$and $\mathrm{CD} 8 \alpha^{+}$lymphocytes was assessed by real-time quantitative PCR. Foxp3 expression was normalized against hypoxanthine-guanine phosphoribosyl transferase expression levels. The data are displayed relative to normalized Foxp3 expression in wild-type $\mathrm{CD}^{+} \mathrm{T}$ cells. The data summarize 3 independent experiments, and the SEM is indicated. The experimental error within an individual experiment was less than $4 \%$ for triplicates. (C) Transfer of CD4 ${ }^{+}$CD25 $5^{+}$-depleted or -nondepleted splenocytes derived from Cat $\mathrm{L}$-deficient or $\mathrm{CD} 4{ }^{+} \mathrm{CD} 25^{+}$-depleted Cat $L-$ sufficient mice into NOD/Scid hosts. The numbers of NOD/Scid recipients of individual cell suspensions are indicated. Diabetes was determined by urine glucose measurements. The data summarize the results of 3 independent experiments. The $\chi^{2}$ test was used to assess statistical significance, and $P$ values are indicated.

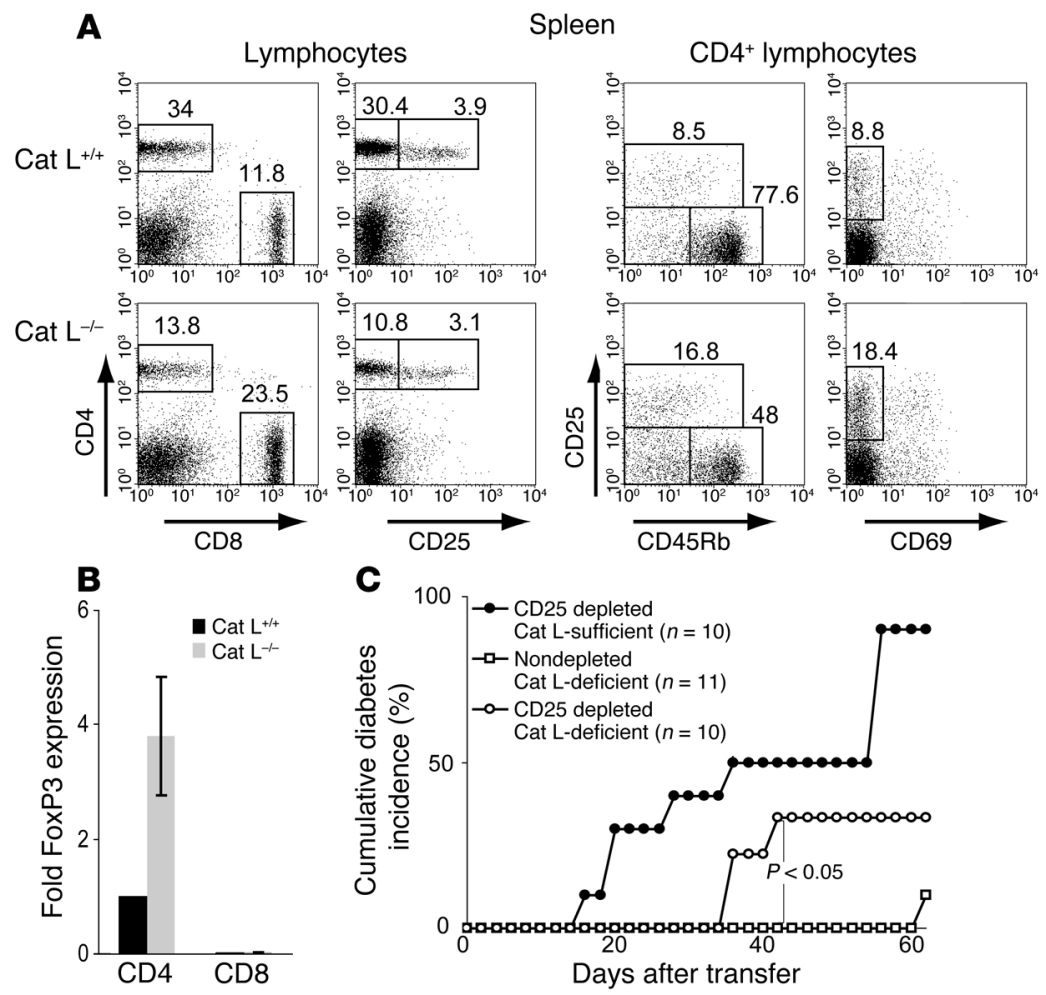




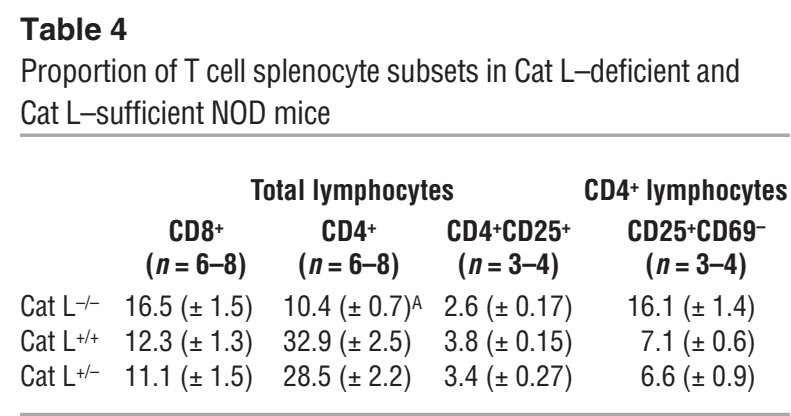

Proportions of $\mathrm{CD}^{+}, \mathrm{CD}^{+}$, and $\mathrm{CD} 4^{+} \mathrm{CD} 25^{+}$lymphocytes (in percentages) are displayed. Percentage of $\mathrm{CD} 25^{+} \mathrm{CD} 69^{-}$cells reflects the cell population in a CD4 lymphocyte gate. Results are expressed as mean \pm SEM. Significant results are indicated. ${ }^{A} P<0.001$

cells in the pancreatic lymph node remain(s) to be identified, they are believed to be dendritic cells (41), as is the case for other peripheral lymphoid organs (reviewed in ref. 42). Interestingly, although Cat $\mathrm{L}$ is present, its activity could not be detected in ex vivo isolated dendritic cells (43). Indeed, peripheral presentation of a pancreatic autoantigen to BDC2.5 TCR transgenic T cells occurred successfully in Cat L-deficient NOD mice. In addition, BDC2.5/NOD and NOD diabetogenic splenocytes transferred into Cat L-deficient NOD mice retained their ability to infiltrate the endocrine pancreas. The ability of a wild-type diabetogenic $\mathrm{T}$ cell repertoire to infiltrate the pancreatic islets suggests that the pancreas is accessible to T cells and implies that class II MHC-restricted antigen presentation of pancreatic autoantigens in general is not impaired in Cat L-deficient mice. Thus, we find no evidence for failed processing of Ii or a general defect in peripheral class II MHC-restricted antigen presentation to explain the lack of progression to diabetes in Cat L-deficient NOD mice.

Thymic selection of $\mathrm{CD}^{+} \mathrm{T}$ lymphocytes is less efficient in Cat $\mathrm{L}$-deficient mice, not only for the $\mathrm{H}-2^{\mathrm{b}}$ and $\mathrm{H}-2^{\mathrm{q}}$ haplotype $(13,14)$ but also for the $\mathrm{H}-2^{\mathrm{g} 7}$ and $\mathrm{H}-2^{\mathrm{d}}$ haplotype (this study). The decrease in $\mathrm{CD}^{+} \mathrm{T}$ cell number is considered to arise from impaired positive selection by a peptide repertoire that differs between Cat L-deficient and wild-type mice (14). Given the broader survey of haplotypes for which this defect is now reported, it is difficult to envision how a single protease would influence the peptide repertoire of an array of class II MHC molecules such that the $\mathrm{CD}^{+} \mathrm{T}$ cell compartment would be consistently and similarly diminished in all cases. If an altered peptide repertoire were at the heart of the reduction in numbers of $\mathrm{CD}^{+} \mathrm{T}$ cells, then variation in the severity of this reduction would be expected, depending on the MHC haplotype examined.

A thymic selection defect is observed after transfer of bone marrow from TCR transgenic mice in the I-A $\mathrm{A}^{\mathrm{b}}$-restricted Tcli TCR model (14). Selection of BDC2.5 TCR transgenic cells, restricted by $\mathrm{I}-\mathrm{A}^{\mathrm{g}}{ }^{7}$, was similarly defective when Cat $\mathrm{L}$ was absent (Figure $4 \mathrm{C}$ ). However, in the $\mathrm{H}-2^{\mathrm{b}}$ haplotype, Ii remnants accumulate in complex with I-A $\mathrm{A}^{\mathrm{b}}$ molecules in the thymus (13), a phenomenon not observed for the $\mathrm{I}-\mathrm{A}^{\mathrm{g} 7}$ background (Figure 2).

Other mechanisms may explain the poor positive selection of $\mathrm{CD}^{+} \mathrm{T}$ cells in the absence of Cat L. For example, Cat L possesses elastase activity $(44,45)$ and could, through degradation of extracellular matrix components, affect intrathymic migration and hence $T$ cell development as suggested $(10,44)$. However, there is as yet no direct experimental support for altered thymo- cyte trafficking in the absence of Cat L. Proteolytic conversion of inactive lysosomal precursors to their active forms or perturbation of endosomal or surface signaling components might also contribute. Cat $\mathrm{L}$ has further been implicated in transcriptional regulation through localization to the nucleus of a Cat L isoform generated by an alternative translational start site (16). Therefore, it is probably an oversimplification to assume that lysosomal proteases play a role in lymphocyte development solely by shaping peptide repertoires, at the exclusion of other possibilities.

The notion that Cat $\mathrm{L}$ has a key role in the generation of the peptide repertoire important for positive selection of CD4 ${ }^{+} \mathrm{T}$ cells would imply that the peripheral $\mathrm{T}$ cell repertoire itself might be influenced in Cat L-deficient mice. Instead, we find that the repertoire of Cat L-deficient NOD mice retains diabetogenic potential as these cells can cause diabetes and/or insulitis upon transfer into NOD/Scid mice, at least to some extent (Figure 5C).

The $\mathrm{CD}^{+} \mathrm{T}$ cell selection defect in Cat $\mathrm{L}$-deficient mice causes a reduction of approximately $70 \%$ in the peripheral $\mathrm{CD}^{+} \mathrm{T}$ cell compartment of $\mathrm{H}-2^{27} \mathrm{NOD}$ mice. This reduction is modest compared with the greater than $85 \%$ reduction in $\mathrm{CD}^{+} \mathrm{T}$ cell number in class II transactivator-deficient (CIITA-deficient) NOD mice (46). However, CIITA-deficient NOD mice exhibit both perivascular and parenchymal infiltrates of the pancreas (46). Further, the Cat L-deficient mice are qualitatively different from CIITA-deficient mice, as class II MHC antigen presentation seems unaffected in the periphery of Cat L-deficient mice whereas CIITA-deficient animals largely lack class II MHC expression. Thus the lack of diabetes and striking reduction in insulitis is unlikely to be the consequence of simply the decrease in numbers of CD $4^{+} \mathrm{T}$ cells. Interestingly, the lack of diabetes in a lymphopenic Cat L-deficient animal is at odds with theories proposing lymphopenia to be a requirement for autoimmunity (47).

$\mathrm{CD}^{+} \mathrm{T}$ regulatory cells contribute to the etiology of a number of autoimmune diseases (reviewed in ref. 29). Regulatory T cells act to maintain peripheral self tolerance via the suppression of autoreactive $\mathrm{T}$ cell clones. In the NOD model, impaired $\mathrm{CD}^{+} \mathrm{T}$ regulatory cell numbers $(48,49)$ and function $(50)$ have been reported, although these points have been debated (51). In the absence of Cat $\mathrm{L}$, the ratio of $\mathrm{CD}^{+} \mathrm{T}$ cell populations was altered in favor of $\mathrm{CD}^{+} \mathrm{CD} 25^{+} \mathrm{T}$ cells. This skewing in favor of cells possessing a regulatory phenotype was also reflected by increased Foxp3 levels in the CD4 ${ }^{+} \mathrm{T}$ cell compartment. Cat L-deficient splenocytes transferred into NOD/Scid recipients were impaired in their ability to elicit diabetes compared with Cat L sufficient controls. Upon removal of $\mathrm{CD}^{+} \mathrm{CD}_{25} 5^{+}$regulatory T cells, however, the Cat $\mathrm{L}-$ deficient splenocytes were capable of provoking autoimmune disease.

\section{Table 5}

Absolute numbers of splenocytes in Cat L-deficient and Cat L-sufficient NOD mice

\begin{tabular}{lcccc}
\hline & $\begin{array}{c}\text { Splenocytes } \\
(\boldsymbol{n = 6 - 8})\end{array}$ & $\begin{array}{c}\mathbf{C D 8}^{+} \\
(\boldsymbol{n}=\mathbf{6 - 8})\end{array}$ & $\begin{array}{c}\mathbf{C D 4}^{+} \\
(\boldsymbol{n}=\mathbf{6 - 8})\end{array}$ & $\begin{array}{c}\mathbf{C D 4}^{+} \mathbf{C D 2 5} \\
(\boldsymbol{n}=\mathbf{3}-\mathbf{4})\end{array}$ \\
Cat $\mathrm{L}^{-/-}$ & $45.9( \pm 3.4)$ & $11.0( \pm 1.4)$ & $3.0( \pm 0.4)^{\mathrm{A}}$ & $0.8( \pm 0.03)$ \\
Cat $\mathrm{L}^{++}$ & $46.1( \pm 4.2)$ & $8.9( \pm 1.3)$ & $10.1( \pm 1.7)$ & $1.4( \pm 0.17)$ \\
Cat $\mathrm{L}^{+-}$ & $46.5( \pm 3.9)$ & $8.3( \pm 1.3)$ & $9.5( \pm 0.9)$ & $1.3( \pm 0.08)$
\end{tabular}

Total number $\left(\times 10^{6}\right)$ of splenocytes are displayed. Results are expressed as mean \pm SEM. Significant results are indicated. ${ }^{A} P<0.001$. 
Therefore, the failure to elicit autoimmunity in Cat L-deficient NOD mice is most likely due to a shift in the frequency of regulatory versus pathogenic $\mathrm{T}$ cell subsets.

The increased proportion of $\mathrm{CD} 4^{+} \mathrm{CD} 25^{+} \mathrm{T}$ cells in the absence of Cat $\mathrm{L}$ is also of interest in light of the debate on the origin of regulatory T cells. Several authors have proposed that differentiation along this lineage is induced by recognition of agonist self ligand by developing thymocytes (52-54). On the other hand, recent data have led to the proposal that it is enhanced survival rather than induced differentiation that leads to an apparent increase in regulatory $\mathrm{T}$ cell numbers in the presence of agonist $(55,56)$. Whatever the mechanism through which Cat $\mathrm{L}$ deficiency perturbs the selection of conventional $\mathrm{CD} 4^{+} \mathrm{T}$ cells, it is not instrumental for the development of regulatory $\mathrm{T}$ cells, reinforcing the notion that the 2 lineages have quite different modes of selection.

In conclusion, we have demonstrated a defect in the $\mathrm{T}$ cell compartment of Cat L-deficient NOD mice that impairs pancreatic islet infiltration in a spontaneous autoimmune disease model. Proteases might therefore provide a target to modulate an autoimmune response. Disruption of Cat S activity influences progression of induced autoimmune disease such as collagen-induced arthritis (38) and Sjögren syndrome (57). In the case of a Cat $\mathrm{S}$ deficiency, the protection from the induced autoimmune response is likely to be due to modulation of antigen presentation. Our study shows that lysosomal proteases may also contribute to homeostasis of the $\mathrm{CD} 4^{+} \mathrm{T}$ cell compartment, with important consequences for development of a spontaneous autoimmune response.

\section{Methods}

Mice. C57BL/6, Balb/c, NOD/Lt, NOD/Thy1.1, and NOD/Scid mice were purchased from the Jackson Laboratory. Generation of BDC2.5/NOD TCR transgenic (28) and Cat L-deficient $\left(\mathrm{H}-2^{\mathrm{b}}\right)$ (17) mice has been described. BDC2.5 Thy1 mice were obtained through breeding of NOD/Thy1 mice with BDC2.5/NOD TCR transgenic mice. Cat L-deficient NOD mice were generated through backcrossing the Cat L deficiency (17) onto the NOD/Lt background for at least 10 generations. Cat L-deficient NOD/Scid mice were generated by intercrossing Cat L-deficient NOD with NOD/Scid mice. Balb/c Cat L mice were generated through backcrossing the Cat $\mathrm{L}$ deficiency to the Balb/c mice for 6 generations. Cat L-deficient BDC2.5/ NOD mice were generated by breeding backcrossed Cat L-deficient NOD mice with BDC2.5/NOD mice. Although the transgenic TCR is encoded on the same chromosome as the disrupted Cat L gene, we were able to obtain mice that carried both the BDC2.5 TCR and the Cat L disruption through a meiotic recombination event. The mice were maintained under pathogen-free conditions at Harvard Medical School according to institutional guidelines. The Institutional Animal Care and Use Committee at Harvard Medical School approved all studies.

Assessment of diabetes and insulitis. From 10 weeks of age, urine glucose levels of mice were measured with Diastix (Bayer). Mice were considered diabetic after 2 consecutive measurements exceeding $250 \mathrm{mg} / \mathrm{dl}$, and the first positive measurement was defined as the onset of diabetes. To assess the level of insulitis, the pancreas was excised, fixed in Bouin's solution, and embedded in paraffin. Nonconsecutive sectioning was followed by H\&E staining. The severity of insulitis was scored on individual islets. Noninvasive infiltration was scored as peri-insulitis. Infiltration of the pancreatic islet was subdivided into nonextensive insulitis $(<50 \%$ of the islet was infiltrated) and extensive insulitis (>50\% of the islet was infiltrated or destroyed).
Metabolic labeling and immunoprecipitation. Splenic single-cell suspensions were incubated for 1 hour in starvation media. Cells were pulsed for 45 minutes with $0.5 \mathrm{mCi} / \mathrm{ml}\left[{ }^{35} \mathrm{~S}\right]$ methionine/cysteine and chased for 4 hours in chase media (RPMI supplemented with $10 \%$ FCS, L-glutamine, penicillin, and streptomycin). LHVS was added 10 minutes before the pulse when indicated. At each time point, cells were spun down, and the pellet was resuspended in $1 \mathrm{ml}$ buffer A ( $50 \mathrm{mM}$ Tris $\mathrm{pH} 7.4,5 \mathrm{mM} \mathrm{MgCl}_{2}$, and $0.5 \%$ NP-40 with complete protease inhibitor mix; Roche Diagnostics Corp.). After cell lysis on ice, cell debris and nuclei were removed by centrifugation. Lysates were precleared with $5 \mu \mathrm{l}$ rabbit and $5 \mu \mathrm{l}$ mouse serum together with $100 \mu \mathrm{l}$ StaphA and subsequently with $100 \mu \mathrm{l}$ StaphA alone. Immunoprecipitations were carried out for 1 hour with $100 \mu \mathrm{l} \mathrm{StaphA}$ and $3 \mu \mathrm{l}$ polyclonal rabbit anti-I-A $\beta$ cytoplasmic tail (JV2) or polyclonal rabbit antiIi cytoplasmic tail (JV5) (21). Immunoprecipitates were washed 3 times in buffer B (50 mM Tris pH 7.4, $150 \mathrm{mM} \mathrm{NaCl}, 5 \mathrm{mM}$ EDTA, and 0.5\% NP-40) and resuspended in sample loading buffer. Samples were boiled or kept at room temperature and analyzed by SDS PAGE. Radioactively labeled polypeptides were visualized by fluorography using DMSO-PPO and exposure to Kodak X-OMAT film.

Immunoblotting. Thymi were mechanically disrupted, processed in buffer $\mathrm{A}$, and analyzed by SDS-PAGE. Cell lysate equivalent to $25 \mu \mathrm{g}$ protein was loaded per lane. Immunoblotting was conducted according to standard techniques with the JV5 antibody.

Cell preparation and flow cytometry. Flow cytometric analysis was performed according to standard procedures. In brief, organs from adult mice were mechanically disrupted, and red blood cells were lysed by hypotonic lysis. Cells were surface stained on ice with a combination of FITC-, PE-, APC-, and PerCP-conjugated antibodies. Incubation with biotinylated antibodies was followed by a secondary staining with streptavidin-APC or streptavidin-PerCP (BD Biosciences - Pharmingen). Stained cells were acquired on FACSCalibur and data were analyzed using CELLQuest software version 3.3 (BD). Events were collected within a lymphoid gate based on forwardand side-scatter profiles. Anti-CD4 (RM4-5), -CD8 $\alpha$ (53-6.7), -CD45RB (C363.16A), -CD25 (7D4 and PC61), -CD69 (H1.2F3), and -Thy1.1 (OX-7) were obtained from BD Biosciences - Pharmingen.

For cell sorting of T cells, splenocytes were depleted of B220-positive cells by using MACS (Miltenyi Biotec). The B220-negative splenocytes were surface stained for $\mathrm{CD} 4, \mathrm{CD} 8 \alpha$, and $\mathrm{CD} 25$ and sorted using a dual laser FACSDiva (BD).

BDC2.5/NOD T cell activation. BDC2.5/NOD T cell activation was determined as described (39). Single-cell suspensions of splenocytes at $2 \times 10^{7} /$ $\mathrm{ml}$ in PBS/0.1\% BSA were labeled with $10 \mu \mathrm{M}$ CFSE (Invitrogen Corp.) for 10 minutes at $37^{\circ} \mathrm{C}$. The reaction was stopped by washing the cells with excess DMEM $/ 10 \%$ FCS. The cells were adjusted to $10^{8}$ cells $/ \mathrm{ml}$ in PBS $/ 0.1 \%$ BSA. In each experiment, $200 \mu$ l CFSE-labeled cells was injected via retro-orbital injection. After 65 hours, the pancreatic and inguinal lymph nodes were removed, and $\mathrm{CD} 4^{+}$cells were analyzed for dilution of the CFSE signal.

Adoptive transfer. To transfer diabetes from female BDC2.5/NOD mice to Cat L-deficient and wild-type female NOD/Scid mice, $5 \times 10^{5}$ red blood cell-depleted BDC2.5/NOD splenocytes were injected i.p.

Transfer of diabetes from recently diabetic NOD mice (as detected by measurements of urine glucose) was essentially conducted as described (46). Recipient Cat L-deficient NOD and control littermate mice were sublethally irradiated (7.25 Gy). After red blood cell lysis, $1.5-2 \times 10^{7}$ splenocytes were administered into 6- to 10-week-old recipient mice via i.v. injection. After 6 weeks, animals were sacrificed and the pancreata submitted for histology.

Bone marrow reconstitution. Recipient mice were lethally irradiated ( 9.5 Gy) 6 hours before bone marrow transfer. The BDC2.5/Thy1.1 NOD 
donor bone marrow was harvested, red blood cells lysed, and $\mathrm{T}$ cells depleted with anti-CD8 $\alpha$ and CD4 MACS beads (Miltenyi Biotec). The recipients received $4 \times 10^{6}$ cells via i.v. injection. The mice were maintained on sulfatrim antibiotic-supplemented water for the duration of the experiment. FACS analysis of the thymi was performed 6 weeks after bone marrow reconstitution.

Real-time quantitative PCR. Total RNA was isolated by standard TRIzol method, and cDNA was prepared using ThermoScript RT-PCR system (Invitrogen Corp.). Real-time quantitative PCR was performed as described (58). The reported mRNA levels were normalized to hypoxanthine-guanine phosphoribosyl transferase expression levels.

Regulatory $T$ cell-depletion assay. Spleens were isolated from wild-type, Cat L-heterozygous, and Cat L-deficient NOD older mice (>15 weeks of age) and single-cell suspensions prepared via mechanical disruption. Cells were stained with anti-CD4 antibodies, anti-CD25 antibodies, and live cell dye Hoechst 33342 (CN Corp.). Live lymphocytes were negatively sorted to deplete $\mathrm{CD} 4{ }^{+} \mathrm{CD} 25^{+}$cells. Final purity of $\mathrm{CD} 4{ }^{+} \mathrm{CD} 25^{+}$-depleted splenocytes was greater than $98 \%$. For each type (wild type, Cat L heterozygous, or Cat $\mathrm{L}$ deficient) $10^{7}$ cells were injected i.p. into 4- to 14-week-old NOD/Scid recipients. Diabetes was monitored as described.

Statistics. For comparison of cell numbers and insulitis between Cat L-deficient and wild-type NOD mice, the 2-tailed unpaired Student's $t$ test was used; $P$ values less than 0.001 were considered significant. To assess differences in cumulative diabetes, the $\chi^{2}$ test was used. $P$ values are indicated.

\section{Acknowledgments}

We thank R. Bronson for help with histology, N. Barteneva and G. Losyev for assistance with cell sorting, and E. Hyatt and the Juvenile Diabetes Research Foundation Center for Immune Tolerance in Diabetes for mice. Thanks to S. Turley and M. Schmidt-Supprian for technical advice and critical reading of the manuscript. We are grateful to K. Kumazaki for help with statistical analysis. R. Maehr received a graduate fellowship from the Boehringer Ingelheim Fonds. J.D. Mintern was supported by a CJ Martin postdoctoral fellowship (National Health and Medical Research Council, Canberra, Australia). A.E. Herman was supported by an NIH training grant to the Dana-Farber/Harvard Cancer Center (T32 CA 70083-07). This work was supported by NIH grants.

Received for publication April 28, 2005, and accepted in revised form July 19, 2005.

Address correspondence to: Hidde L. Ploegh, Department of Pathology, Harvard Medical School, 77 Avenue Louis Pasteur, Boston, Massachusetts 02115, USA. Phone: (617) 432-4776; Fax: (617) 432-4775; E-mail: ploegh@hms.harvard.edu.

Ana-Maria Lennon-Duménil's present address is: INSERM 520, Institut Curie, Paris, France.
1. Tisch, R., and McDevitt, H. 1996. Insulin-dependent diabetes mellitus. Cell. 85:291-297.

2. Castano, L., and Eisenbarth, G.S. 1990. Type-I diabetes: a chronic autoimmune disease of human, mouse, and rat. Annu. Rev. Immunol. 8:647-679.

3. Wicker, L.S., Todd, J.A., and Peterson, L.B. 1995. Genetic control of autoimmune diabetes in the NOD mouse. Annu. Rev. Immunol. 13:179-200.

4. Wucherpfennig, K.W. 2003. MHC-linked susceptibility to type 1 diabetes: a structural perspective. Ann. N. Y. Acad. Sci. 1005:119-127.

5. Bryant, P.W., Lennon-Dumenil, A.M., Fiebiger, E., Lagaudriere-Gesbert, C., and Ploegh, H.L. 2002. Proteolysis and antigen presentation by MHC class II molecules. Adv. Immunol. 80:71-114.

6. Amigorena, S., et al. 1995. Invariant chain cleavage and peptide loading in major histocompatibility complex class II vesicles. J. Exp. Med. 181:1729-1741.

7. Neefjes, J.J., and Ploegh, H.L. 1992. Inhibition of endosomal proteolytic activity by leupeptin blocks surface expression of MHC class II molecules and their conversion to SDS resistance alpha beta heterodimers in endosomes. EMBO J. 11:411-416.

8. Brachet, V., Raposo, G., Amigorena, S., and Mellman, I. 1997. Ii chain controls the transport of major histocompatibility complex class II molecules to and from lysosomes. J. Cell Biol. 137:51-65.

9. Honey, K., and Rudensky, A.Y. 2003. Lysosomal cysteine proteases regulate antigen presentation. Nat. Rev. Immunol. 3:472-482.

10. Lennon-Dumenil, A.M., et al. 2002. A closer look at proteolysis and MHC-class-II-restricted antigen presentation. Curr. Opin. Immunol. 14:15-21.

11. Pluger, E.B., et al. 2002. Specific role for cathepsin $\mathrm{S}$ in the generation of antigenic peptides in vivo. Eur. J. Immunol. 32:467-476.

12. Hsieh, C.S., deRoos, P., Honey, K., Beers, C., and Rudensky, A.Y. 2002. A role for cathepsin L and cathepsin $\mathrm{S}$ in peptide generation for MHC class II presentation. J. Immunol. 168:2618-2625.

13. Nakagawa, T., et al. 1998. Cathepsin L: critical role in Ii degradation and CD4 T cell selection in the thymus. Science. 280:450-453.

14. Honey, K., Nakagawa, T., Peters, C., and Rudensky, A. 2002. Cathepsin L regulates CD4+ T cell selec- tion independently of its effect on invariant chain: a role in the generation of positively selecting peptide ligands. J. Exp. Med. 195:1349-1358.

15. Wolters, P.J., and Chapman, H.A. 2000. Importance of lysosomal cysteine proteases in lung disease. Respir. Res. 1:170-177.

16. Goulet, B., et al. 2004. A cathepsin L isoform that is devoid of a signal peptide localizes to the nucleus in $\mathrm{S}$ phase and processes the CDP/Cux transcription factor. Mol. Cell. 14:207-219.

17. Roth, W., et al. 2000. Cathepsin L deficiency as molecular defect of furless: hyperproliferation of keratinocytes and pertubation of hair follicle cycling. FASEB J. 14:2075-2086.

18. Haskins, K., and Wegmann, D. 1996. Diabetogenic T-cell clones. Diabetes. 45:1299-1305.

19. Riese, R.J., et al. 1996. Essential role for cathepsin S in MHC class II-associated invariant chain processing and peptide loading. Immunity. 4:357-366.

20. Shi, G.P., et al. 1999. Cathepsin S required for normal MHC class II peptide loading and germinal center development. Immunity. 10:197-206.

21. Driessen, C., et al. 1999. Cathepsin S controls the trafficking and maturation of MHC class II molecules in dendritic cells. J. Cell Biol. 147:775-790.

22. Villadangos, J.A., Riese, R.J., Peters, C., Chapman, H.A., and Ploegh, H.L. 1997. Degradation of mouse invariant chain: roles of cathepsins S and D and the influence of major histocompatibility complex polymorphism. J. Exp. Med. 186:549-560.

23. Watts, C. 2004. The exogenous pathway for antigen presentation on major histocompatibility complex class II and CD1 molecules. Nat. Immunol. 5:685-692.

24. Palmer,J.T., Rasnick, D., Klaus, J.L., and Bromme, D. 1995. Vinyl sulfones as mechanism-based cysteine protease inhibitors. J. Med. Chem. 38:3193-3196.

25. Germain, R.N., and Hendrix, L.R. 1991. MHC class II structure, occupancy and surface expression determined by post-endoplasmic reticulum antigen binding. Nature. 353:134-139.

26. Carrasco-Marin, E., Shimizu, J., Kanagawa, O., and Unanue, E.R. 1996. The class II MHC I-Ag7 molecules from non-obese diabetic mice are poor peptide binders. J. Immunol. 156:450-458.

27. Carrasco-Marin, E., Kanagawa, O., and Unanue,
E.R. 1997. Insights into the chemistry and biology of the I-Ag7 class II molecule. Res. Immunol. 148:291-301.

28. Katz, J.D., Wang, B., Haskins, K., Benoist, C., and Mathis, D. 1993. Following a diabetogenic $\mathrm{T}$ cell from genesis through pathogenesis. Cell. 74:1089-1100.

29. Sakaguchi, S., et al. 2001. Immunologic tolerance maintained by CD25+ CD4+ regulatory T cells: their common role in controlling autoimmunity, tumor immunity, and transplantation tolerance. Immunol. Rev. 182:18-32.

30. Singh, B., et al. 2001. Control of intestinal inflammation by regulatory $\mathrm{T}$ cells. Immunol. Rev. 182:190-200.

31. Annacker, O., et al. 2001. CD25+ CD4+ T cells regulate the expansion of peripheral CD4 $\mathrm{T}$ cells through the production of IL-10. J. Immunol. 166:3008-3018.

32. Hori, S., Nomura, T., and Sakaguchi, S. 2003. Control of regulatory $\mathrm{T}$ cell development by the transcription factor Foxp3. Science. 299:1057-1061.

33. Herman, A.E., Freeman, G.J., Mathis, D., and Benoist, C. 2004. CD4+CD25+ T regulatory cells dependent on ICOS promote regulation of effector cells in the prediabetic lesion. J. Exp. Med. 199:1479-1489.

34. Khattri, R., Cox, T., Yasayko, S.A., and Ramsdell, F. 2003. An essential role for Scurfin in CD4+CD25+ T regulatory cells. Nat. Immunol. 4:337-342.

35. Fontenot, J.D., Gavin, M.A., and Rudensky, A.Y. 2003. Foxp3 programs the development and function of CD $4+\mathrm{CD} 25+$ regulatory T cells. Nat. Immunol. 4:330-336.

36. Ghosh, S., et al. 1993. Polygenic control of autoimmune diabetes in nonobese diabetic mice. Nat. Genet. 4:404-409.

37. McAleer, M.A., et al. 1995. Crosses of NOD mice with the related NON strain. A polygenic model for IDDM. Diabetes. 44:1186-1195.

38. Nakagawa, T.Y., et al. 1999. Impaired invariant chain degradation and antigen presentation and diminished collagen-induced arthritis in cathepsin S null mice. Immunity. 10:207-217.

39. Hoglund, P., et al. 1999. Initiation of autoimmune diabetes by developmentally regulated presenta- 
tion of islet cell antigens in the pancreatic lymph nodes. J. Exp. Med. 189:331-339.

40. Gagnerault, M.C., Luan, J.J., Lotton, C., and Lepault, F. 2002. Pancreatic lymph nodes are required for priming of beta cell reactive T cells in NOD mice. J. Exp. Med. 196:369-377.

41. Turley, S., Poirot, L., Hattori, M., Benoist, C., and Mathis, D. 2003. Physiological beta cell death triggers priming of self-reactive $\mathrm{T}$ cells by dendritic cells in a type-1 diabetes model. J. Exp. Med. 198:1527-1537.

42. Jenkins, M.K., et al. 2001. In vivo activation of antigen-specific CD4 T cells. Annu. Rev. Immunol. 19:23-45.

43. Honey, K., et al. 2001. Cathepsin S regulates the expression of cathepsin L and the turnover of gamma-interferon-inducible lysosomal thiol reductase in B lymphocytes. J. Biol. Chem. 276:22573-22578

44. Fiebiger, E., et al. 2002. Invariant chain controls the activity of extracellular cathepsin L. J. Exp. Med. 196:1263-1269.

45. Felbor, U., et al. 2000. Secreted cathepsin L generates endostatin from collagen XVIII. EMBO J. 19:1187-1194.

46. Mora, C., Wong, F.S., Chang, C.H., and Flavell,
R.A. 1999. Pancreatic infiltration but not diabetes occurs in the relative absence of MHC class IIrestricted CD4 T cells: studies using NOD/CIITAdeficient mice. J. Immunol. 162:4576-4588.

47. King, C., Ilic, A., Koelsch, K., and Sarvetnick, N. 2004. Homeostatic expansion of T cells during immune insufficiency generates autoimmunity. Cell. 117:265-277.

48. Salomon, B., et al. 2000. B7/CD28 costimulation is essential for the homeostasis of the CD4+CD25+ immunoregulatory $\mathrm{T}$ cells that control autoimmune diabetes. Immunity. 12:431-440.

49. Delovitch, T.L., and Singh, B. 1997. The nonobese diabetic mouse as a model of autoimmune diabetes: immune dysregulation gets the NOD. Immunity. 7:727-738

50. Gregori, S., Giarratana, N., Smiroldo, S., and Adorini, L. 2003. Dynamics of pathogenic and suppressor $\mathrm{T}$ cells in autoimmune diabetes development. J. Immunol. 171:4040-4047.

51. Berzins, S.P., Venanzi, E.S., Benoist, C., and Mathis, D. 2003. T-cell compartments of prediabetic NOD mice. Diabetes. 52:327-334.

52. Jordan, M.S., et al. 2001. Thymic selection of $\mathrm{CD} 4+\mathrm{CD} 25+$ regulatory $\mathrm{T}$ cells induced by an agonist self-peptide. Nat. Immunol. 2:301-306.
53. Apostolou, I., Sarukhan, A., Klein, L., and von Boehmer, H. 2002. Origin of regulatory T cells with known specificity for antigen. Nat. Immunol. 3:756-763.

54. Yamashiro, H., Hozumi, N., and Nakano, N. 2002. Development of CD25(+) T cells secreting transforming growth factor-beta 1 by altered peptide ligands expressed as self-antigens. Int. Immunol. 14:857-865.

55. van Santen, H.M., Benoist, C., and Mathis, D. 2004. Number of T reg cells that differentiate does not increase upon encounter of agonist ligand on thymic epithelial cells. J. Exp. Med. 200:1221-1230.

56. Liston, A., et al. 2004. Gene dosage-limiting role of Aire in thymic expression, clonal deletion, and organ-specific autoimmunity. J. Exp. Med. 200:1015-1026.

57. Saegusa, K., et al. 2002. Cathepsin S inhibitor prevents autoantigen presentation and autoimmunity. J. Clin. Invest. 110:361-369. doi:10.1172/ JCI200214682.

58. Schmidt-Supprian, M., et al. 2004. Differential dependence of CD4+CD25+ regulatory and natural killer-like $T$ cells on signals leading to NF-kappaB activation. Proc. Natl. Acad. Sci. U. S. A. 101:4566-4571. 